\title{
On the relationship of orography with extreme dry spells in Greece
}

\author{
C. Oikonomou ${ }^{1}$, H. A. Flocas ${ }^{1}$, G. Katavoutas ${ }^{1}$, M. Hatzaki ${ }^{1}$, D. N. Asimakopoulos ${ }^{1}$, and C. Zerefos ${ }^{2}$ \\ ${ }^{1}$ Department of Environmental Physics and Meteorology, Faculty of Physics, University of Athens, Greece \\ ${ }^{2}$ Department of Climatology and Atmospheric Environment, Faculty of Geology and Geoenvironment, University of Athens, \\ University of Athens, Greece
}

Received: 20 October 2009 - Revised: 14 May 2010 - Accepted: 17 May 2010 - Published: 15 June 2010

\begin{abstract}
The objective of this study is to investigate the relationship of orography over Greece with prolonged dry spells, as represented by the maximum number consecutive dry days (CDD index) during an extremely dry summer. For this purpose a simulation experiment was conducted with the aid of the regional climate model RegCM3.1 using a spatial resolution of $10 \mathrm{~km}$. It was shown that a significant precipitation regime formed over the mountainous areas of continental Greece and Crete during this dry summer, due to orographically forced precipitation, consequently influencing the length of dry spells. Furthermore, the CDD appears spatial variations over the maritime areas, despite the zero or insignificant precipitation. The sensitivity test that was performed with the elimination of orography demonstrated the important role that orography plays in the distribution of $\mathrm{CDD}$, since significant lengthening of extreme dry spells was found over the mountainous areas.
\end{abstract}

\section{Introduction}

Precipitation regime in Greece is highly irregular on spatial and temporal scale, being controlled by atmospheric circulation as well as by complex orography, sea surface temperature distribution and land/sea interaction (Xoplaki et al., 2000; Bartzokas et al., 2003; Maheras et al., 2004). The largest amount of winter precipitation is recorded in western Greece, as imposed by the longest mountain range of the mainland (Pindos Mountain) and the eastern Aegean islands while during summer the maximum amount of precipitation is noted mainly over the Pindos mountain range, and the minimum over the southern Aegean and Ionian Sea (Lolis et al.,

Correspondence to: $\mathrm{H}$. A. Flocas

(efloca@ phys.uoa.gr)
1999). The longest summer dry periods are found in central and south-eastern Aegean Sea (Anagnostopoulou et al., 2003; Maheras and Anagnostopoulou, 2003).

Over the marine areas, both duration and precipitation amount present their maximum value during January and their minimum, in summer. In north-western Greece, the intra-annual variation of precipitation duration presents two maxima, in December and February. Over the northern mainland areas, there are also two maxima, the first from late October to early December and the second around late May. Over western Greece, western Crete and the eastern Aegean the spatial distribution of precipitation amount presents maxima from mid November to late March, while over the southern marine and coastal areas, the intra-annual variation of precipitation amount and duration is simple, with one broad maximum from mid December to early February (Bartzokas et al., 2003).

While the relationship between precipitation extremes with atmospheric circulation over Greece has been explored in previous studies (Maheras et al., 2004; Tolika et al., 2007; Houssos et al., 2008; Hatzaki et al., 2009; Oikonomou et al., 2010), the role of orography has not been investigated extensively, mainly due to its local scale, creating a growing demand for downscaling applications. For this purpose, a useful tool is a regional climatic model (RCM), since it can represent in detail topographic features, such as mountain barriers, and consequently reveal regional climatic characteristics (Schmidli et al., 2006; Alpert et al., 2008; Zanis et al., 2009a, b) while, at the same time, being able to capture the climate processes and reproduce climatic fields on a seasonal scale effectively and synoptically, unlike mesoscale models which require much computational time and produces a large amount of output meteorological data on a daily scale that are not needed in this climatological study.

Published by Copernicus Publications on behalf of the European Geosciences Union. 


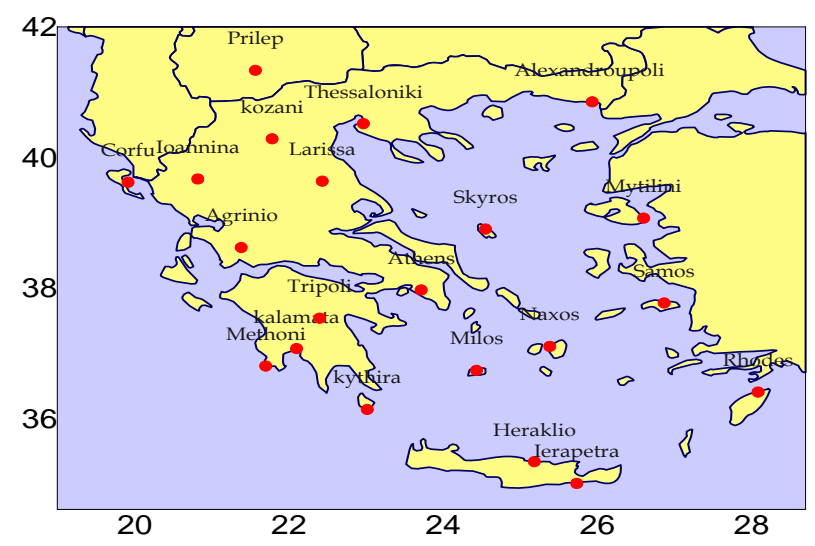

Fig. 1. Locations of the rain gauge stations employed in this study.

Within this context, the objective of this study is to investigate the relationship of orography with the distribution of prolonged dry periods in Greece, during an extremely dry summer, with the aid of the Regional Climate Model RegCM3.1.

\section{Data and methodology}

In order to identify the extreme dry spells, the climatic index CDD was employed, which is defined as the maximum number of consecutive dry days on a seasonal basis. Dry day is defined as the one with daily precipitation amount less than $1 \mathrm{~mm}$. The simulation was performed for the summer period (June, July, August) of 1993, when the CDD value in 20 stations in Greece and 1 station in FYROM exceeded the corresponding 0.95 percentile for the period 1958-2000, as was found by Oikonomou et al. (2010). The value of the CDD index was estimated between 20 days (Tripoli) and 92 days (Agrinio), while the 0.95 percentile for each station ranges from 58 days (Tripoli) to 72 days (Agrinio). The station data were obtained through the European project STARDEX (STAtistical and Regional dynamical Downscaling of EXtremes for European regions) (Fig. 1).

In order to perform the regional climatic simulations, the third generation hydrostatic Regional Climate Model RegCM3.1 was employed (Pal et al., 2007), that was originally developed at the National Center for Atmospheric Research (NCAR) and has been widely used in studies of regional climate and seasonal predictability (Giorgi et al., 2006). This model version shows a noticeable improvement in the representation of the surface hydrological cycle in mountainous regions. The simulation area extends between $24-51^{\circ} \mathrm{N}$ and $8-38^{\circ} \mathrm{E}$, while the study focuses on the Greek area (33-42 $\mathrm{N}$ and $18-28^{\circ} \mathrm{E}$ ) (Fig. 2).

The model was driven by the NCEP NNRP2 Reanalysis datasets $\left(2.5^{\circ} \times 2.5^{\circ}\right.$ grid, L17 level) comprised of the air temperature, geopotential height, relative humidity, wind



Fig. 2. (a) The simulation area; (b) the examined area.

variables, surface pressure and mean sea level pressure. The 10 min resolution terrain (GTOPO30) and land-use Global Land Cover Characterization (GLCC) datasets were used to constrain the surface. The elevation data used derive from the United States Geological Survey (USGS). As for the Sea Surface Temperature input data, the $1^{\circ}$ weekly resolution SST dataset (OI_WK) was employed. For the estimation of convective precipitation, the MIT-Emanuel Convective Precipitation Scheme was selected, since Zanis et al. (2009a) demonstrated that it is more effective at convective precipitation during the warm season in southeastern Europe.

The simulation experiment employs the topography of the examined area shown in Fig. 3 (hereafter will be referred as "real experiment"). Then a sensitivity test was performed where the orography in the examined area was removed (hereafter will be referred as "flat experiment"). Both simulation experiments were conducted with grid resolution of $10 \mathrm{~km}$ and a spin-up time of 1 month, for the period JuneAugust 1993, producing daily precipitation amounts. CDD values were then estimated on a seasonal basis with the aid of the statistical language $\mathrm{R}$.

\section{Results and discussion}

The model was initially validated against station data, by estimating the biases of the model outputs at the nearest grid point to corresponding station for both mean daily precipitation amount and CDD index during the summer of 1993. It should be noted here that the altitude of the station location was, in general, different from the corresponding of the nearest grid point. However, small biases were estimated at all stations, except of two stations, that are located at coastal areas being very close to mountain ranges (Agrinio, Kalamata). It was found that the model performs well during 


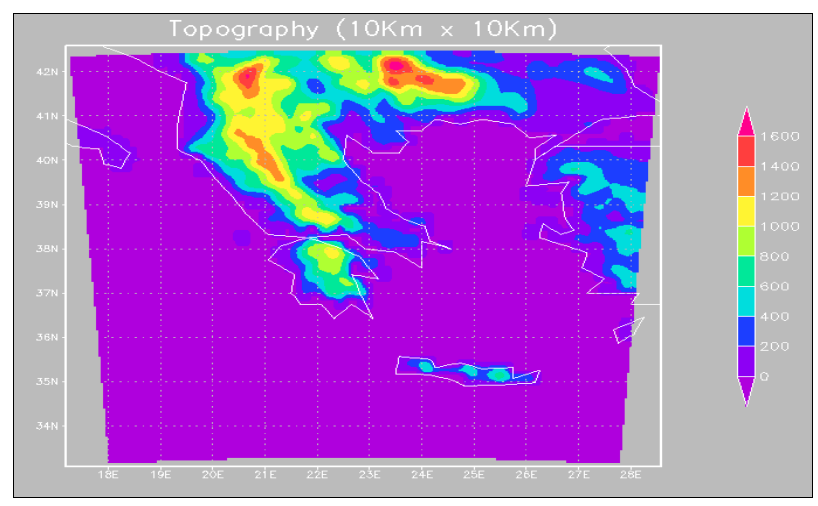

Fig. 3. Orography map of the examined area for the "real experiment".

the examined period, with an overestimation of precipitation in West Greece and a slight underestimation in the Aegean Sea and Crete. Of course, it should be noted that the precipitation amount is very low during summer, thus affecting the performance of all regional climatic models over the examined area (Zanis et al., 2009b). Furthermore, the model underestimates significantly the maximum duration of dry spells over the central continental area. These biases are more likely attributed to inadequate representation of orography and the islands, as well as to parameterization errors of convective precipitation over mountainous areas (Bergant et al., 2007; Dimri and Ganju, 2007). The root mean squared error (RMSE) of the model for the estimation of mean daily precipitation and CDD was $0.76 \mathrm{~mm} /$ day and 31 days, respectively.

The summer of 1993 was mainly characterized by the prevalence of the Persian Gulf trough over Eastern Mediterranean being combined with an extended anticyclone over Southern Europe (see Fig. 4a), causing the establishment of northerly component winds over the Aegean Sea, the so called "Etesians" (Metaxas and Bartzokas, 1994). At 500 $\mathrm{hPa}$ (see Fig. 4b), a large scale trough dominates over Turkey and Levantine Sea, resulting in the formation of an intense height inversion, preventing the development of large scale precipitation (Rodwell and Hoskins, 1996) while a large scale ridge affects much of Greece.

The results of the "real experiment" have demonstrated that precipitation occurs over continental Greece, while there was insignificant or no precipitation over the seas (Fig. 5a). This distribution is consistent with the climatological precipitation regime that was described by Bartzokas et al. (2003) for summer. Moreover, in our case, since the prevailing wind blows from the Aegean Sea, the moist air is forced to lift the mountain barriers along eastern mainland and Crete, producing enhanced convective precipitation upwind the mountain, even near the coast depending on the height of the lifting condensation level (Kotroni et al., 1999; Roe, 2005). The precipitation in northern Greece could be attributed to occasional
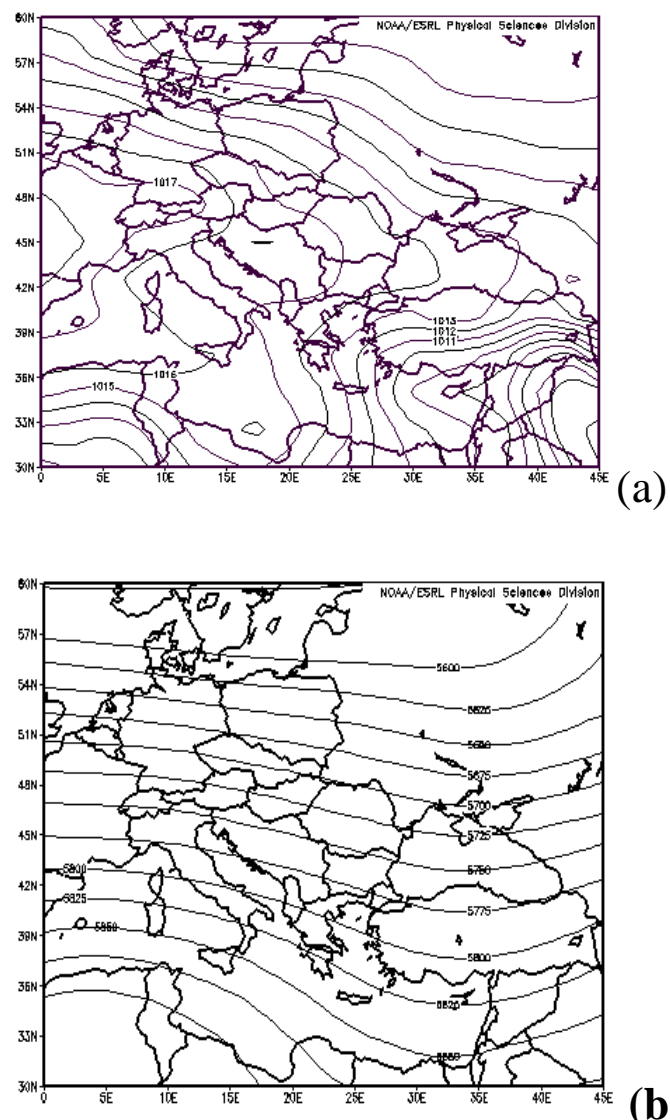

(b)

Fig. 4. Mean distribution for summer 1993 of: (a) mean sea level pressure in hPa and (b) $500 \mathrm{hPa}$ geopotential height in gpm (source: NOAA/ESRL Physical Science Division).

passage of upper level troughs in June and July, associated with cold air masses (Spanos et al., 2003) and the development of thermal convective precipitation (Sioutas and Flocas, 2003). On the contrary, precipitation is lower in the western mainland, except in the area of Pindos, where it is associated with dynamic instability of the humid air being carried by the sea breeze in the western coast and forced by the mountain (Metaxas, 1978; Fotiadi et al., 1999).

During the "flat experiment" the precipitation amount is distributed uniformly over the mainland, without significant variations, as was expected, due to the absence of the complex orography (Fig. 5b). Moreover, a substantial reduction of the precipitation amount is evident in the whole examined area (Fig. 5c), which is greater over mountainous areas that are resolved by the model, of about one third compared to the "real experiment".

Consistent with the precipitation distribution, in the "real experiment" CDD values are reduced over mountainous areas, while maximum values prevail over the south-eastern Aegean Sea (Fig. 6a). Furthermore, southern continental area exhibit longer extreme dry spells than the northern part 


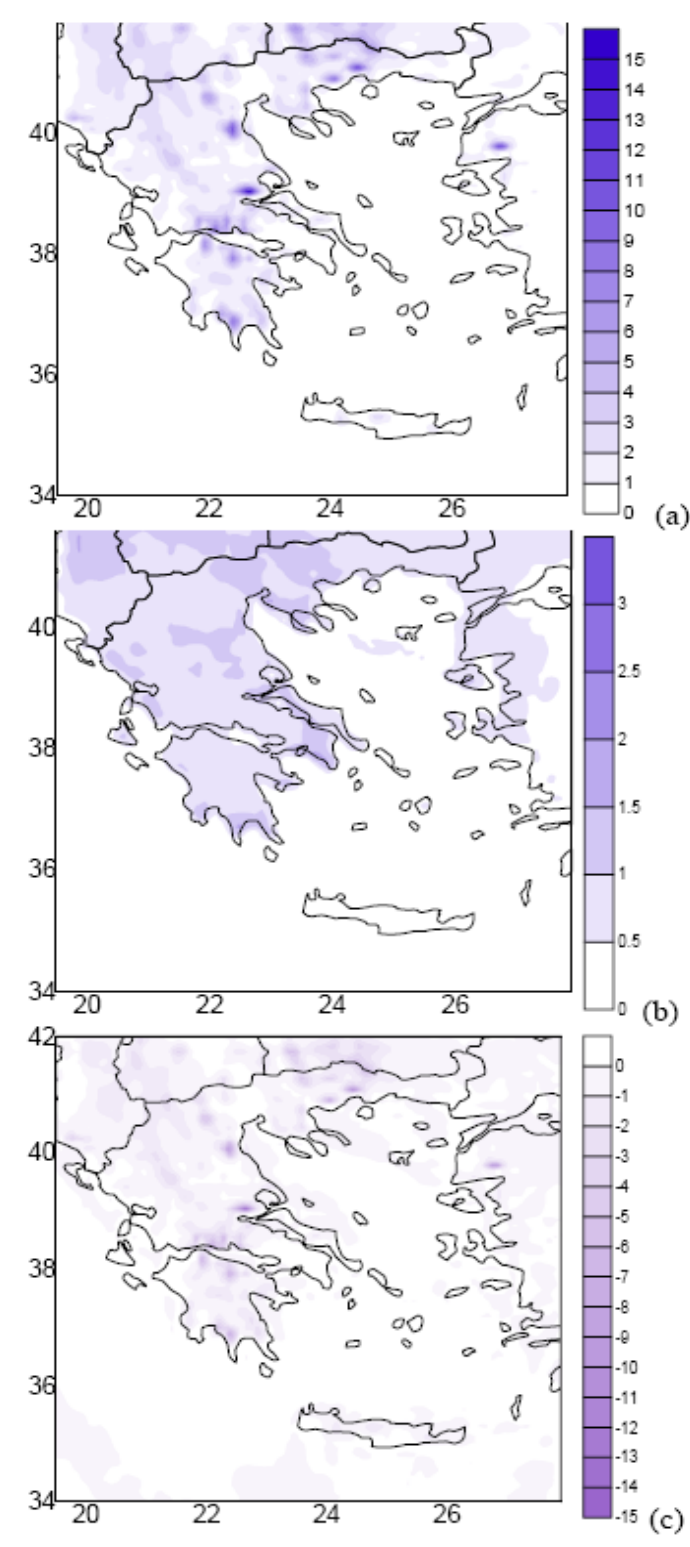

Fig. 5. Model output of mean daily precipitation amount ( $\mathrm{mm} /$ day) for the summer of 1993 for: (a) "real experiment", (b) "flat experiment" and (c) Precipitation bias ("flat" minus "real experiment").

of the mainland, in accordance with the climatological pattern of precipitation duration in summer (Bartzokas et al., 2003). However, CDD distribution in Fig. 6a is characterized by individual features that are related to the sea effect. More specifically, CDD is characterized by smaller values in the northern Aegean Sea and southern Ionian Sea, suggesting that some wet days exhibit very small daily precipitation, due to local instability conditions that shorten the length of dry spells. This is consistent with the large variability of precipitation amount in the southern Ionian Sea during summer, as identified by satellite data (Hatzianastasiou et al., 2008).
In the "flat experiment", the CDD distribution is not as uniform as the precipitation one (Fig. 5b). CDD generally increases over the areas where the main mountain ranges are located (Fig. 6b), following the corresponding precipitation reduction. This is especially evident along western and northern Aegean Sea coasts (Fig. 6c). On the contrary, there is reduction in other maritime areas. The most significant reduction was found in central Aegean Sea (of almost $38 \%$ as compared to the "real experiment"), that is combined with a simulated weakening of the strong northeasterly winds, probably reflecting the channelling effect of the orography along Greece and western Turkey (Repapis et al., 1978; Arseni-Papadimitriou et al., 1988; Kotroni et al., 2001).

\section{Conclusions}

The relationship of orography with precipitation and prolonged dry periods was investigated over Greece, during the extremely dry summer of 1993, with the aid of the regional climate model RegCM3.1. The validation of the model during the examined period demonstrated that the model performs well in the Aegean Sea, but there is an overestimation of precipitation in the continental areas, and consequently an underestimation of the maximum number of consecutive dry days (CDD).

It was found that during the extreme dry summer, precipitation occurred in mountainous areas of Greece, but especially in the eastern side of the continental area, being favoured by the northerly component winds prevailing over the Aegean. On the contrary, minimum or no precipitation amount was noted in the maritime areas. The distribution of CDD follows the precipitation amount distribution: maximum values over southeastern Aegean Sea and smaller values over the mountainous areas. However, there are spatial variations of CDD over the seas.

When orography is removed, the precipitation amount is reduced and the extreme dry periods are lengthened in the mountainous areas of Greece, suggesting the important role of the orographic lifting, even in the summer period when the precipitation amount is small, as compared to the other seasons (Maheras et al., 2004; Tolika et al., 2007). Inversely, the duration of extreme dry periods decreases over northern Aegean Sea, probably reflecting the canalising effect of orography between Greece and western Turkey on prevailing north-easterlies, as was noticed by previous studies.

Apart from the role of the orography during summer, this numerical study implies the contribution of the sea effect, as expressed by the development of local instability, associated with land/sea interaction and/or thermal fluxes and should be further explored. It is worthy to note that although the results refer to one summer, they could be considered representative when similar conditions of atmospheric circulation prevail. It can be supported that the model RegCM3.1 seems to be 




Fig. 6. Model output of CDD values in number of days for the summer of 1993 for: (a) "real experiment"; (b) "flat experiment" and (c) CDD bias ("flat" minus "real experiment").

a valuable tool for studying regional climate in the Eastern Mediterranean region, provided that the model limitations concerning the parameterization of physical processes and the representation of the real terrain and orography are reduced.

Acknowledgements. The present study was funded through the Project "PENED 2003" with 75\% from European Union-European Social Fund (E.S.F.) and 25\% from National Funds-Ministry of Development-General Secretariat of Research and Technology and from private funds.

Edited by: S. C. Michaelides

Reviewed by: two anonymous referees

\section{References}

Alpert, P., Krichak, S. O., Shafir, H., Haim, D., and Osetinsky, I.: Climatic trends to extremes employing regional modelling and statistical interpretation over the E. Mediterranean, Global Planet Change, 63, 163-170, 2008.

Anagnostopoulou, C., Maheras, P., Karacostas, T., and Vafiadis, M.: Spatial and temporal analysis of dry spells in Greece, Theor. Appl. Climatol., 74, 77-91, 2003.

Arseni-Papadimitriou, A., Maheras, P., and Giles, B.: Contribution to the study of the strong north winds on Aegean Sea in warm season, Rivista di Meteorologia Aeronautica 48(3-4), 131-137, 1988.

Bartzokas, A., Lolis, C. J., and Metaxas, D. A.: A study on the intra-annual variation and the spatial distribution of precipitation amount and duration over Greece on a 10-day basis, Int. J. Climatol., 23, 207-222, 2003.

Bergant, K., Belda, M., and Halenka, T.: Systematic errors in the simulation of European climate (1961-2000) with RegCM3 driven by NCEP/NCAR reanalysis, Int. J. Climatol., 27(4), 455472, 2007.

Dimri, A. P. and Ganju, A.: Wintertime Seasonal Scale Simulation over Western Himalaya Using RegCM3, Pure. Appl. Geophys., 164, 1733-1746, 2007.

Fotiadi, A. K., Metaxas, D. A., and Bartzokas, A.: A statistical study of precipitation in NW Greece, Int. J. Climatol., 19, 12211232, 1999.

Giorgi, F., Pal, J. S., Bi, X., Sloan, L., Elguindi, N., and Solmon, F.: Introduction to the TAC special issue: the RegCNET network, Theor. Appl. Climatol., 86, 1-4, 2006.

Hatzaki, M., Flocas, H. A., Giannakopoulos, C., and Maheras, P.: The impact of Eastern Mediterranean Teleconnection Pattern on eastern Mediterranean climate, J. Climate., 22, 977-992, 2009.

Hatzianastasiou, N., Katsoulis, B., Pnevmatikos, J., and Antakis, V.: Spatial and temporal variation of precipitation in Greece and surrounding regions based on global precipitation climatology project data, J. Climate., 21, 1349-1370, 2008.

Houssos, E. E., Lolis, C. J., and Bartzokas, A.: Atmospheric circulation patterns associated with extreme precipitation amounts in Greece, Adv. Geosci., 17, 5-11, 2008, http://www.adv-geosci.net/17/5/2008/.

Kotroni,V., Lagouvardos, K., Kallos, G., and Ziakopoulos, D.: Severe flooding over central and southern Greece associated with pre-cold frontal orographic lifting, Q. J. Roy. Meteor. Soc., 125, 967-991, 1999.

Kotroni, V., Lagouvardos K, and Lalas D.: The effect of the island of Crete on the etesian winds over the Aegean Sea, Q. J. Roy. Meteor. Soc., 127, 1917-1937, 2001.

Lolis, C. J., Bartzokas A., and Metaxas, D. A.: Spatial covariability of the climatic parameters in the Greek area, Int. J. Climatol., 19, 185-196, 1999.

Maheras, P. and Anagnostopoulou, C.: Circulation Types and their Influence on the interannual variability and precipitation changes in Greece, Mediterranean Climate-Variability and Trends, Springer Verlag, Berlin, Heidelberg, 215-239, 2003.

Maheras, P., Tolika, K., Anagnostopolou, C., Vafiadis, M., Patrikas, I., and Flocas, H. A.: On the relationships between circulation types and changes in rainfall variability in Greece, Int. J. Climatol., 24, 1695-1712, 2004.

Metaxas, D. A.: Evidence on the importance of diabatic heating as 
divergence factor in the Mediterranean, Arch. Meteor. Geophy. A., 27A, 69-80, 1978.

Metaxas, D. A. and Bartzokas, A.: Pressure covariability over the Atlantic, Europe and N. Africa. Application: centers of action for temperature, winter precipitation and summer winds in Athens, Greece, Theor. Appl. Climatol., 49, 9-18, 1994.

Oikonomou, C., Flocas, H., Hatzaki, M., Nisantzi, A., and Asimakopoulos D. N: Relationship of extreme dry spells in Eastern Mediterranean with large scale circulation, Theor. Appl. Climatol., 100, 137-151, 2010.

Pal., J. S., Giorgi, F., Bi, X., Elguindi, N., Solmon, F., Gao, X., Rauscher, S. A., Francisco, R., Zakey, A., Winter, J., Ashfaq, M., Syed, F. S, Bell, J., Diffenbaugh, N., Karmacharya, J., Konare, A., Martinez, D., da Rocha, R., Sloan, L. C., and Steiner, A.: Regional climate modeling for the developing world:the ICTP RegCM3 and RegCNET, B. Am. Meteorol. Soc., 88, 1395-1409, 2007.

Repapis, C. C., Zerefos, C., and Tritakis, B.: On the etesians over the Aegean, Proc. Acad. Athens, 572-606, 1978.

Rodwell, M. J. and Hoskins, B. J.: Monsoons and the dynamics of the deserts, Q. J. Roy. Meteor. Soc., 122, 1385-1404, 1996.

Roe, G. H.: Orographic precipitation, Annu. Rev. Earth Pl. Sc., 33, 645-671, 2005.

Schmidli, J., Frei, C., and Widale P. L.: Downscaling from GCM precipitation: a benchmark for dynamical and statistical downscaling methods, Int. J. Climatol., 26, 679-689, 2006.
Sioutas, M. and Flocas, H. A.: Hailstorms in Northern Greece: synoptic patterns and thermodynamic environment, Theor. Appl. Climatol., 75, 189-202, 2003.

Spanos, S., Maheras, P., Karacostas, T., and Pennas, P.: Objective climatology of $500 \mathrm{hPa}$ cyclones in central and east Mediterranean region during warm-dry period of the year, Theor. Appl. Climatol., 75, 167-178, 2003.

Tolika, K., Maheras, P., Vafiadis, M., Flocas, H. A., and ArseniPapadimitriou, A.: Simulation of seasonal precipitation and raindays over Greece: a statistical downscaling technique based on artificial neural networks (ANNs), Int. J. Climatol., 27, 61-881, 2007.

Xoplaki, E., Luterbacher, J., Burkard, R., Patrikas, I., and Maheras, P.: Connection between the large-scale $500 \mathrm{hPa}$ geopotential height fields and precipitation over Greece during wintertime, Clim. Res., 14(2), 129-146, 2000.

Zanis, P., Douvis, K., Kapsomenakis, I., Kioutsioukis, I., Melas, D., and Pal, J. S.: A sensitivity study of the Regional Climate Model (RegCM3) to the convective scheme with emphasis in central eastern and southeastern Europe, Theor Appl. Climatol., 97, 327-337, 2009a.

Zanis, P., Kapsomenakis, I., Philandras, C., Douvis, K., Nikolakis, D., Kanellopoulou, E., Zerefos, C., and Repapis, C.: Analysis of an ensemble of present day and future regional climate simulations for Greece, Int. J. Climatol., 29, 1614-1633, 2009 b. 